\title{
Design of ultraprecision machine tools with applications to manufacture of miniature and micro components
}

Journal of Materials Processing Technology, Volume 167, Issues 2-3, 30 August 2005, Pages

$515-528$

\author{
Xichun Luo ${ }^{+}$, Kai Cheng ${ }^{*}$ and Dave Webb \\ School of Technology, Leeds Metropolitan University, Leeds LS1 3HE, UK \\ Frank Wardle \\ Loadpoint Ltd, Chelworth Industrial Estate, Cricklade, Swindon, Wilts SN6 6HE, UK
}

\begin{abstract}
Currently the underlying necessities for predictability, producibility and productivity remain big issues in ultraprecision machining of miniature/microproducts. The demand on rapid and economic fabrication of miniature/microproducts with complex shapes has also made new challenges for ultraprecision machine tool design. In this paper the design for an ultraprecision machine tool is introduced by describing its key machine elements and machine tool design procedures. The focus is on the review and assessment of the state-of-the-art ultraprecision machining tools. It also illustrates the application promise of miniature/microproducts. The trends on machine tool development, tooling, workpiece material and machining processes are pointed out.
\end{abstract}

*Correspondence to Professor Kai Cheng

School of Technology, Leeds Metropolitan University, Leeds LS1 3HE UK

Tel: 01132836731 Fax: 01132833110 E-mail: k.cheng@,leedsmet.ac.uk

+ Currently work at: School of Industrial \& Manufacturing Science, Cranfield University, MK43 0AL, UK 
Keywords: Ultraprecision machines design; ultraprecision machining; miniature and micro components manufacturing; 3D microstructures and devices; bench-type ultraprecision machines

*Correspondence to Professor Kai Cheng School of Technology, Leeds Metropolitan University, Leeds LS1 3HE UK

Tel: 01132836731 Fax: 01132833110 E-mail: k.cheng@,leedsmet.ac.uk

+ Currently work at: School of Industrial \& Manufacturing Science, Cranfield University, MK43 0AL, UK 


\section{Introduction}

It is widely appreciated that the development of precision manufacturing has greatly changed our lives in terms of increased living standards. High precision manufacturing offers quality and reliability for conventional products, but also makes possible entirely new products, especially where mechatronics, miniaturization and high performance are important [1]. Impressive examples are digital cameras, mobile phones, minimal invasive medical equipment as well as biotechnological or chemical processing equipment [2]. The high function density and reduced size and weight will make the miniature and micro products more competitive. As the result the markets for miniature and micro components and products hold a high potential of growth [2].

Recently new demands in the fabrication of miniature/microproducts have appeared, such as the manufacture of microstructures and components with 3D complex shapes or free-form surfaces. It is found that those microstructures possess some special functions including light guiding, anti-reflective and self-clean, etc. The microstructures will further improve the performance of miniature and micro products. Furthermore, fabrication of real 3D miniaturized structures and free-form surfaces are also driven by the integration of multiple functions in one product.

Currently MEMS is one of major driving forces for making micro-components. Silicon is a classical material for MEMS or Microsystems, but many other materials have meanwhile appeared for the increasing number of applications fields which are becoming relevant for micro products. For examples: The life science as an emerging application area of MEMS requires glass, ceramics, metal and plastics rather than only silicon as raw materials of micro components. 
Although traditional mechanical ultraprecision machining has be used as a major means to fabricate miniature and micro components/products, it still remains a big issue in the predictability, producibility and productivity of fabrication of miniature/microproducts, especially for those miniature and micro components/products with complex surface forms/shapes. The ultraprecision machine tools design and machining technology will have to be changed so as to achieve a rapid and economic fabrication of those components and products in a variety of engineering materials and ensure the machines and technology easily accessible to the wider audience (including SMEs) of precision engineering.

The focus in this paper will be on the design of ultraprecision machine tools especially for fabrication of miniature and micro components/products. The design guidelines for the machine and its key elements will be described and the start-of-the-art of the commercially available machines critically reviewed. The applications of microfabrications will be illustrated and design of bench-type ultraprecision machines and their applications will be further explored. The papers will conclude with a discussion on the future trends in the subject area.

\section{Design of ultraprecision machine tools}

Fig.1 illustrates a 3-axis ultraprecision milling machine - UPM 3, designed and built at the IPT in Aachen [3]. As other ultraprecision machine tools it consists of four major sub-systems. They are mechanical structure, spindle and drive system, controller and system, and measurement and 
inspection system. These sub-systems are essential, even though tooling and processing technologies are equally important.

\subsection{Mechanical structure}

Mechanical structure consists of stationary and moving bodies. The stationary bodies include machine base, column and spindle box housing, etc. They usually carry moving bodies, such as worktables, slides, spindles and carriages.

The structural design is critical since the structure of a machine provides the mechanical support for all of the machine's components. When considered in the context of the design of the machine as a system, some of the major design issues include [4]:

- Stiffness and damping

- Structural configuration

- Structural connectivity

- Structure dynamic performance (such as thermal stability and response to external forces)

With regard to the proper functioning of moving axes and operational stability the structural design will follow the following principles:

- High structural loop stiffness: The structural loop includes the spindle shaft, the bearing and housing, the slideway and frame, the drives, and the cutting tool and work-holding fixtures. All mechanical components and joins in the propagation path from the drive to the point of reaction, e.g. the end-effector (cutting tool) or the centre of gravity, must have a high stiffness to avoid deformation under changing loads [5]. 
- Good damping property: This can be achieved by choosing high damping capability material as machine bed and slideway materials or filling structure's cavities with lead shot and oil for viscous and mass damping or concrete for mass damping. Some methods, such as shear plate and tuned mass damper, can also be applied to damp structures [4].

- Symmetry and closed loop structural configuration: "T" configuration is popularly used for most of the ultraprecision turning and grinding machines. Recently a novel tetrahedron structure proposed by the NPL in England has been applied in an ultraprecision grinding machine - Tetraform C. It utilizes an internally damped space frame with all the loads carried in closed loop. The design generates a very high static stiffness coupled with exceptional dynamic stiffness [6].

- Thermal and elastic structural loops: Minimizing the influence of spatial thermal gradients in the system and making the system quickly reach and maintain a stable equilibrium.

- Minimization of heat deformation: Reduction of thermal deformation from the view point of the structural design rather than the remedy by using the control technique. The methods include separating heat sources from the machine and processes, quickly expelling the heat generated within the machine and maintaining the fluid used for heat removal at a constant temperature, using zero or low thermal expansion materials. LODTM developed at LLNL employs several ingenious methods removing the heat-related errors. For instance, the LODTM is enclosed in a container within which the air temperature is maintained at $20 \pm 0.010^{\circ} \mathrm{C}$. The measurement frame is made from Superinva and covered by a shell in which water maintained at $20 \pm 0.001{ }^{\circ} \mathrm{C}$ is circulated. The housing for the main spindle bearing incorporates a coolant conductor in which temperature controlled water is circulated to remove any heat generated by bearings before it causes excessive deformation. As a result 
of these measures, the maximum drift due to heat deformation over a 24 hour period is less than $25 \mathrm{~nm}[4]$.

- Isolation of environmental effects: Closed-machining environment is essential to isolate the disturbances coming from outer circumstance surrounding the machine, e.g. vibrations from the floor, fluctuation of the room temperature, heat transfer from other machines, floating dust and so on [7].

The choice of materials for a machine tool is one of key factors in determining final machine performance. Many criteria may be considered, including temporal stability, specific stiffness, homogeneity, easiness of manufacturing and cost, etc [5].

Cast iron and granite are most widely used materials for the machine base and slideways because of their good wear resistance, low thermal expansions, low stress-caused deformation and high vibration damping capacity, albeit there is increasing usage of polymer concretes in the past few years. The drawback of granite is that it can absorb moister so it is used in dry environment. For this reason many builders seal the granite with epoxy resin. For obtaining light weight with high damping capacity and rigidity, polymer concrete becomes popular especially for some precision instruments and small sizes of machine tools. In some application cases, structural materials of low thermal expansion coefficient and high dimensional stability have been used; among those are super-invar, synthetic granite, ceramics and Zerodur [8].

2.2 Work spindles 
Spindle is a key element of the precision machine tool because the spindle motion error will have significant effects on the surface quality and accuracy of machined components. The most often used spindles in precision machine tools are aerostatic spindles and hydrostatic spindles. They both have high motion accuracy and capable of high rotational speed. An aerostatic spindle has lower stiffness than an oil hydrostatic spindle, but it has lower thermal deformation than oil hydrostatic spindle. Aerostatic spindles are widely used in machine tools with medium and small loading capacity while hydrostatic spindles are often applied in large heavy-load precision machine tools.

Recently groove technique has been used in the design of air bearings. The grooved hybrid air bearing combines aerostatic and aerodynamic design principles to optimize ultra high speed performance. Aerostatic lift is generated by feeding the bearing with pressurized air through orifice restrictors as in the conventional bearing design [9]. Aerodynamic lift is controlled by the additional helical grooves machined onto the shaft or bearing journal surfaces. The benefits of grooves in the bearing include significantly changing the pressure distribution within the bearing and improving load carrying capability and stiffness. The groove also changes the air velocity gradients in the bearing affecting the basic mechanism of whirl instability, which usually improves the threshold oat from which instability occurs [9].

Fig. 2 shows the air bearing spindles developed by Fraunhofer IPT, Philips, Zeiss and Cranfield Precision for UPM 3 [10]. Combining the spiral groove technology with an externally pressurized bearing type, a maximum rotational speed of $100,000 \mathrm{rpm}$ and radial stiffness of 30 $\mathrm{N} / \mu \mathrm{m}$ are achieved in radial direction with a total error motion below $100 \mathrm{~nm}$ [10]. 
Air bearing slideways, air/magnetic bearing slideways, oil hydrostatic bearing slideways, and air bearing rotary tables are widely used in the state-of-the-art ultraprecision machine tools as they are capable of high motion accuracy. Oil hydrostatic bearings are often used in large machine tools because of their high load capability, although the additional pumping system, environmental and thermal issues need to be taken account of.

\subsection{Drives}

The moving mechanism is grouped into spindle and feed drives in machine tools. The spindle drive provides sufficient angular speed, torque and power to a rotating spindle held in the spindle housing with magnetic or air bearings. The electric AC motor and DC brushless motor for high speed spindles are always built into the spindle to reduce the inertia and friction produced by the motor-spindle shaft coupling. The air turbine spindle is also applied in ultraprecision machine tools.

The piezoelectric actuator is a kind of short stroke actuator. It is very promising for application in the rotary table drive and slideways drive because of its high motion accuracy and wide response bandwidth. Currently, piezoelectric actuators have been applied in the design of the fine tool-positioner in order to obtain high precision motion of the cutting tool. The piezoelectric actuator combined with mechanical flexure hinge is often used for positioning control of the diamond cutting tool. More recently, Fast Tool Servo (FTS) system has been introduced for diamond turning components and products with structured and non-rotationally symmetric surfaces such as laser mirrors, ophthalmic lenses and lenses molds, etc [11]. 
Linear motor direct drives and friction drives are two kinds of long stroke drives used on ultraprecision machine tools. Friction drive is very predictable and reproducible due to a prescribed level of preload at the statically determinate wheel contacts, thereby superior in machining optically smooth surfaces. One of the good applications of friction drives is on the UPM 3 with a friction wheel drive for $\mathrm{X}$ axis, which has form accuracy less than $0.2 \mu \mathrm{m} / 100$ $\mathrm{mm}$ as achieved [11]. Linear motor drives can offer the system designer an elegant alternative in that they produce linear motion directly and therefore eliminate the need for conversion mechanisms such as lead-screws, belt drives, and rack \& pinions, with potentially better performance in terms of stiffness, acceleration, speed, smoothness of motion, accuracy and repeatability, etc [28].

\subsection{Control}

The control sub-system includes motors, amplifiers, switches and the controller that are used to energize the electrical parts in a controlled sequence and time. High speed, multi-axis CNC controllers are essential for efficient control of, not only servo drives in high precision position loop synchronism for contouring, but also thermal and geometrical error compensation, optimized tool setting and direct entry of the equation of shapes (avoiding lengthy postprocessing) [8]. By applying feedback control the control resolutions in nanometer even subnanometer scales could be obtained. The use of advanced PC based control systems will be the trend for low cost ultra-precision machine tools in the future.

2.5 Metrology and inspection system 
Metrology and inspection systems are the basis for ultraprecision machining to be widely applied in industry. On the other hand higher level accuracy assurance in metrology and inspection is also a drive for ultraprecision machining towards higher precision requested for future engineering industry. Fast and accurate positioning of the cutting tool towards the workpiece surface and monitoring of the tool conditions visually by the operator should be integrated into the inspection system especially for on-line operation purposes.

Laser metrology incorporated into the machine tool is widely used for feed and position control at the resolution down to nanometer or sub-nanometer level. Capacitance gages, LVDT (Linear Variable Differential Transducer) and photoeletronic sensors are normally employed in the detection of nanometric displacement over small working distances [8].

Here it takes the laser interferometery metrology system as shown in Fig. 3 as a case study. Tool tip must be precisely positioned in the $\mathrm{X}$ and $\mathrm{Z}$ directions. In order to satisfy Abbe's principle, the laser interferometer shown in Fig. 3 is used for the tool position control. For the $\mathrm{X}$ direction, a pair of straightedges, one on each side of the tool bar, acts as the kinematic reference. To measure the position in the $\mathrm{X}$ direction, two beams are directed against each of the straightedges (i.e. a total of four beams). The tool bar's pitch angle error is corrected using the upper and lower laser beams, while the mean value of the measurements from both sides is used to eliminate errors caused by axisymmetric expansion of the frame [12].

For measurements in the $\mathrm{Z}$ direction (the tool's height), a pair of laser beams is directed against a pair of straightedges parallel to the tables as the kinematic reference. With a mirror attached to 
the bottom face of the tool bar (to get as close to the tool tip as possible), a third laser beam in the $\mathrm{Z}$ direction measures the tool's position. The earlier pair of laser beams in the $\mathrm{Z}$ direction is used to eliminate errors of the tool bar rotating about the $\mathrm{X}$ axis [12].

In addition to incorporating Abbe's principle, this laser interferometer has another special design for high precision measurement, i.e. the laser beam conduits contain a vacuum [12].

2.6 Main features of ultraprecision machine tools

The main features of an ultraprecision machine tool can be classified as:

- Machine tool structure with high loop stiffness, high natural frequency and good damping characteristics

- High thermal and mechanical stability

- Low vibrations

- High precision axis of motion

- High precision control

2.7 Design process for an ultraprecision machine tool

As illustrated in Fig. 4 the design of an ultraprecision machine tool requires five basic steps: task definition, conceptual design, layout design, detail design and design follow-up [4], albeit the full design process is always iterative, parallel, non-linear, multidisciplinary and open-ended to any innovative and rational ideas and improvements. The purpose of task definition is to determine the machine functions and specifications. The functional requirements of an ultraprecision machine may address the considerations in geometric, kinematics, dynamics, 
power requirement, materials, sensor and control, safety, ergnomics, production, assembly, quality control, transport, maintenances, cost and schedule, etc. In this stage it needs to perform assessment of the state-of-the-art technology to make the design more competitive and the cost reasonable. The final specifications will be determined after several specification iterations. The following conceptual design is very important for the innovation of the machine design. Brainstorming is the method most often thought of for generating concept design [4]. Several design schemes may be proposed in this stage, which are followed by kinematics analysis, thermo-mechanic analysis, static analysis, dynamics analysis and control system analysis. The analysis results, together with error budget and cost estimation, will be used to check the conformance to the machine's specifications and finally choose the best design scheme. Once a conceptual design is finished a design plan can be formulated for detail design. In detailed design stage it will finish the design of mechanical system design, controller, sensor and electronic system, electrical, hydraulic and pneumatic support system. After the detailed design is completed there is still much work that needs to be done in order to make the design successful, including develop a test and user support program, update design and documents etc. [4]. The application needs and tooling and processing techniques applied are constantly the inputs to the design process.

\section{Current ultraprecision machine tools}

This section will briefly introduce several commercially available typical ultraprecision machine tools in the light of demonstrating the state-of-the-art of ultraprecision machine tools applied in the industry. 


\subsection{Diamond turning machines}

Single point diamond turning has long been a well established technology for the fabrication of a wide range of non-ferrous metals, crystals and polymers. Nanotch 350 UPL (Moore Nanotechnology system Ltd.) and Nanoform 350 (Precistech Ltd.) are two widely used diamond turning machines with $350 \mathrm{~mm}$ of swing capability. Here it takes Nanoform 350 UPL as an example to explain its configuration. This two-axis ultraprecision lathe is characterized as "T" axis configuration. As shown in Fig. 5 the $\mathrm{X}$ slide moves spindle box along $\mathrm{X}$ direction, while diamond cutting tool is moved along $\mathrm{Z}$ direction by $\mathrm{Z}$ slide [13]. Both slides are built on the machine base and vertical to each other. They are also in the same height so as to improve motion accuracy. Nanotech 350 UPL employs high stiffness hydrostatic slideways, state-of-theart linear motors with sinusoidal drive amplifiers and a 6,000 rpm heavy-duty groove compensated air bearing work spindle with liquid cooling for long-term thermal stability [14].

With Nanotech 350UPL components used in the electro-optics, aerospace, consumer electronics and computer industries can be machined with good surface finish (in several nanometres) and high form accuracy (in ten of nanometres). Nanotech 350 UPL has optional grinding system for micro-grinding optical components and direct grinding of lens molds in non-diamond machinable materials such as metals and ceramics.

\subsection{Diamond grinding machines}

Diamond grinding allows access to more materials than diamond turning. It is capable of fabrication of a range of materials including optical glass, crystals, ferrous metals, polymers and ceramics. Nanotech 500FG (Moore Nanotechnology System Ltd.) is a typical multi-axis 
diamond grinding machine. It is capable of generating arbitrary conformal optical surface (including non-spherical and non-axisymmetric) shapes within a $250 \mathrm{~mm} \times 250 \mathrm{~mm} \times 300 \mathrm{~mm}$ machining envelope. As shown in Fig. 6, Nanotech 500FG has three linear axes. They are the independently mounted $\mathrm{X}$ and $\mathrm{Z}$ axis with a " $\mathrm{T}$ " configuration and $\mathrm{Y}$ axis mounted integral to $\mathrm{Z}$ axis to eliminate "stacked" axes. The slideways stiffness is $350 \mathrm{~N} / \mu \mathrm{m}$. The motion accuracy of work spindle is lower than $50 \mathrm{~nm}$. Rotary table (B-axis) is used to carry the grinding spindle. When replacing the grinding spindle with a diamond tool, the machine is also capable of turning operations [15].

Nanotech 500FG is capable of generating components with non-axisymmetric and axisymmetric geometrics, such as conformal optics with spherical, aspherics, cylindrical, conical geometries; lenses \& mould inserts; F-Theta Lenses; aspheric lenses \& mirrors; diffractive element; polygons and prisms [15].

To pursue a more rigidity structure an ultraprecision grinding machine - PicoAce machine with novel pyramidal space frame structure was commissioned by Loadpoint Ltd recently. PicoAce is suitable for traverse grinding of flat or convex work surfaces up to a maximum of $\phi 305 \mathrm{~mm}$ diameter or plunge grinding of flat surfaces to a maximum diameter of $\phi 200 \mathrm{~mm}$. The general arrangement of PicoAce is shown in Fig. 7 [16], the principal machine elements: cup wheel grinding spindle, rotary work table, $\mathrm{X}$ and $\mathrm{Z}$ slideways are mounted in a closed loop structure. The structure takes the form of a pyramid shape frame fixed to a solid rectangular base. The cup wheel spindle has a vertical axis and is arranged to slide up and down in a cylindrical $\mathrm{Z}$ slideway positioned centrally over the base. Directly beneath the wheel spindle is the rotary 
table mounted on the X slidway. With this novel structure the static loop stiffness of PicoAce is $100 \mathrm{~N} / \mu \mathrm{m}$ in vertical direction. High motion resolution of $1 \mathrm{~nm}$ is achieved in $\mathrm{Z}$ axis. It can produce optical quality surface finishes with low levels of subsurface damage on a range of hard and brittle materials [16].

\subsection{Micro-milling machines}

Kugler MICROMASTER $\mathrm{MM}^{\circledR}$ is a high-precision $\mathrm{CNC}$ controlled 5-axis milling machine. It is developed by the Fraunhofer IPT in Aachen and Kugler Ltd. to meet the special demands and requirements of micromachining and mechanical micro-structuring. Its configuration is shown in Fig. 8. MICROMASTER MM is equipped with hydrostatic linear guides to improve the stiffness and damping characteristics. Two of slides (X and $\mathrm{Y}$ ) are driven by linear motors to avoid a mechanical coupling between feed drive system and moving components, high resolution linear scales are integrated into these axes. Two additional rotary axes (B and C axes) enable a real 5-axis milling to be carried out on the machine [3]. The machine is based on finegrained granite which ensures highest long term stability. A pneumatic vibration insulation system is used to effectively suppress oscillations with frequencies in the range $>5 \mathrm{~Hz}$. Depending on the choice of machining spindles and tools, a variety of non-ferrous metals, brittle and hard materials can be processed with high precision. The arbitrarily programmable CNC-control for process sequences and machining paths also enables the manufacturing of microstructure and free-form surfaces with almost optical quality [17].

Fanuc Robonano $\alpha-0 i \mathrm{~A}$ is another well-known 5-aixs milling machine. The machine configuration is shown in Fig. 9 [18]. The work rotary table (B axis) is carried by X slide. Y 
slide is for vertical movement, which strokes $20 \mathrm{~mm}$. Z slides can move the milling cutting system in a direction normal to the X-Y plane. The Robonano machine is characterized with the friction-free servo mechanism as aerostatic bearings are employed in the translational and rotary axes. The aerostatic slideways are connected through floating nut slide mechanism to aerostatic leadscrew. 1 nanometer positioning and smooth feed are realised by the 64 million pulse encoders and aerostatic bearing AC servo motor. Another character of the Robonano machine is the high speed air turbo spindle and high precision chucking mechanism. In Robonano machine high speed air turbine spindle with a diamond milling tool, driven by air, is set on the B axis or $\mathrm{C}$ axis table. The side of both ends of the turbine blade and the radial part of the spindle shaft are supported from aerostatic bearings. A piezoelectric device is built in between the spindle and a bracket to control the position of cutting edge minutely. Because turbine drives only develop useful power over a narrow range and the machine uses three spindles to cover a wide speed range (20,000 to $100,000 \mathrm{rpm})$. Robonano machine has been applied in 3D precision machining and optics mould manufacturing (moulds for diffraction grating and aspheric lenses) [18].

3.4 Main specifications of the ultraprecision machine tools

The main specifications of the ultraprecision machine tools described above are summarized in Table 1. The data and information listed in Table 1 provide a good comparison of the design, specifications, applications and characteristics of the commercially available ultraprecision machine tools. 
Table 1 Main specifications of five typical commercial ultraprecision machine tools.

\begin{tabular}{|c|c|c|c|c|c|}
\hline & Nanotech 350UPL & Nanotech 500FG & PicoAce & Micromaster ${ }^{\circledR}$ MM & Robonano $\alpha$-0iA \\
\hline Base Structure & $\begin{array}{l}\text { Cast, epoxy/granite } \\
\text { composite }\end{array}$ & $\begin{array}{l}\text { Monolithic natural } \\
\text { granite, } \mathrm{Z} \text { axis riser }\end{array}$ & Cast iron & Fine grained granite & $\begin{array}{l}\text { Cast iron base with } \\
\text { concrete }\end{array}$ \\
\hline Vibration isolation & $\begin{array}{l}\text { Three point passive } \\
\text { air isolation system }\end{array}$ & $\begin{array}{l}\text { Three point passive } \\
\text { air isolation system }\end{array}$ & $\mathrm{N} / \mathrm{A}$ & $\begin{array}{l}\text { Pneumatic vibration } \\
\text { isolation }\end{array}$ & Air and oil damper \\
\hline Spindles & $\begin{array}{l}\text { Air bearing (liquid } \\
\text { cooled) }\end{array}$ & $\begin{array}{l}\text { Air bearing (Work } \\
\text { spindle) } \\
\text { hydrostatic oil }\end{array}$ & Aerostatic bearing & Air bearing & Air bearing \\
\hline
\end{tabular}




\begin{tabular}{|c|c|c|c|c|c|}
\hline & & bearing(Grinder) & & & \\
\hline Motion accuracy & $<50 \mathrm{~nm}$ & N/A & $<50 \mathrm{~nm}$ & $<100 \mathrm{~nm}$ & $<100 \mathrm{~nm}$ \\
\hline Motion Axes & Hydrostatic slides & Hydrostatic slides & Hydrostatic bearing & $\begin{array}{l}\mathrm{X}, \mathrm{Y} \text { and } \mathrm{Z} \\
\text { (Hydrostatic bearing) } \\
\mathrm{B} \text { axis (mechanical } \\
\text { bearing) } \\
\mathrm{C} \text { axis (Aerostatic } \\
\text { bearing) }\end{array}$ & Aerostatic bearing \\
\hline Drive system & $\begin{array}{l}\text { Brushless DC linear } \\
\text { motor }\end{array}$ & $\begin{array}{l}\text { DC servo motor \& } \\
\text { ball screw }\end{array}$ & $\mathrm{N} / \mathrm{A}$ & Linear motor & AC servo motor \\
\hline Resolution & $0.034 \mathrm{~nm}$ & $8.6 \mathrm{~nm}$ & $1 \mathrm{~nm}$ (Z slide) & N/A & $1 \mathrm{~nm}(\mathrm{X}, \mathrm{Z})$ \\
\hline
\end{tabular}




\section{Applications of micro and miniature products}

Fig. 10 illustrates the promising application area of micro and miniature products and Microsystems [19]. It also anticipates that micro products will have more and more applications around the world. It is very interesting to see that IT peripherals are still the biggest market of micro products. In 2005 the total turnover of microproducts is anticipated to reach US\$ 38 billion, which is two times of the total turnover in 2000 . Ultraprecision machining can be applied in bulk machining of silicon, aluminum substrates for computer memory disks etc. In other areas such as biomedical, automotive, household and telecommunication the total turnovers of micro products are still steadily growing. Ultraprecision machining is also very promising in the production of sensors, accelerometer, actuators, micro-mirror, fiber optics connectors and micro-displays. Although by 2006, IT is expected to lose its predominant position due to new MEMSbased applications in sectors such as biotechnology and communications (optical and radio frequency switching for example will become a major growth area) [20]. The microproducts are normally integrated products of some electronics, mechanical parts and optical parts while in miniature or micro dimensions. In fact only small number of microproducts solely relies on electronics. The mechanical and optical parts are of significant importance for micro products. Fig. 11 obviously shows that the turnovers of mechanical and optical parts are dominant in the total turnover of microproducts. It provides confidence that the market figure of ultraprecision technologies, even taking account of unforeseen future applications in microproducts, will be high. Therefore the tendency of nano/micro machining will be the fabrication of micro mechanical and 
optical components with complex geometric features (freeform and microstructures) and their replication moulds.

The main miniature and micro products will be MEMS, mechanical components, optical devices, micro dies and molds, and other 3D micro-devices, etc.

MEMS is still a major driving force for microproducts. Micro machining provides a cost effectively solution for low volume production or prototypes of MEMS since no expensive masks are needed. It can also be used to produce 3D complex masks for mass production of MEMS. Fig. 12 illustrates a silicon wafer structuring. The microstructure will result in an increase of solar cell efficiency by multiple reflection of light (light trap) through increase of active surfaces [10].

Ultraprecision machining can efficiently manufacture micro-mechanical components, such as micro-sensor (pressure, flow, and gas), micro-actuator, micro-motors, micropump, micro-valves, encoder disks and fiber-optic mechanical components, etc. Fig. 13 shows a spherical end face of a fiber-optic connector which is ground by using resin bond diamond cup wheel [21]. The average surface roughness $\mathrm{Ra}$ is $6.9 \mathrm{~nm}$ in the fiber area on the connector, while the surface roughness of the ground ferrule (Zirconia) is $30 \mathrm{~nm}$.

Using single point diamond turning and diamond grinding many micro-optical components can be machined with high form accuracy and good surface finish. These optical components include micro-optics such as camera lens, CCD lens; free-form optics 
such as ophthalmic lenses, scanner mirrors, prisms; retro-reflectors used for street sign, warning sign and clothing; displays for mobile phones, TFT panel, etc. Fig. 14 shows a surface-structured mirror turned by Fast Tool Servo on an ultraprecision lathe [11]. The surface of the mirror consists of a rotationally symmetrical part on which a nonrotationally symmetrical surface with 90 facets is superimposed. The mirror is used as an integrator optic to enhance the beam quality in high power lasers [11].

The indispensable advantage of single point diamond turning, micro milling and nanogrinding are applicable on manufacture of 3D complex shape/form micro moulds, dies and embossing tooling for mass production of optical and mechanical parts. In fact this should be the focus of micro machining. It is anticipated that micro machining will be intensively used in the fabrication of compressive moulds and injection moulds. Fig.15 shows an injection moulding tool for matchmaking machined by micro milling [22]. The material of the mould is hardened steel (54 HRC), its position and form tolerance at workpiece is $\pm 5 \mu \mathrm{m}$, and surface finish $\mathrm{Ra}>0.25 \mu \mathrm{m}$. The diameter of smallest milling cutter is $0.2 \mathrm{~mm}$. The total machining time is $50 \mathrm{~min}$ [22].

\section{Trends in the fabrication of miniature and micro products}

Machining accuracy and high quality surface generation depend on machine tool accuracy, tooling, workpiece material and operational factors which are well applicable in manufacture of miniature and micro components and products. 


\subsection{Trends of ultraprecision machine tools}

The trend in ultraprecision machining will be cutting down machining cost while maintaining high accuracy. However, so far most of micro machining is undertaken using conventional size ultraprecision machine tools. This will of course increase the investment and operation costs which make the manufacturing SMEs difficult access the high-value added technology/business. Development of bench-type ultraprecision machine tools and the associated nano-micro machining technology may lead to wider application of ultraprecision machining technology and their application in fabrication of miniature and micro components/products in particular.

The benefits of the bench type machines may include:

- Low machine production costs

- Small space and energy-efficient

- Ease of localized environmental control (temperature and vibrations, etc) and friendliness and thus low operation costs

- Affordable manufacturing technology

Fig. 16 illustrates the design layout of a bench-type micro milling machine which is currently being developed by the authors with the support of the EU MASMICRO project [30]. The machine aims at manufacturing the miniature and micro components in various engineering materials, such as:

(1) MEMS (Si)

- Complex microstructures 
- Microgrooves

(2) Optical components (Glass, polymer, Al)

- Complex shape or freeform optics (lenses, mirrors, prisms)

- Lens shutters, displays, light guiding microstructures

(3) Medical components (Polymer, glass)

- Ophthalmics (Contact lens)

- Dentistry

(4) Mechanical components (Al, steel)

- Microsensors (pressure, flow, gas)

- Fiber optic-mechanical components (filter, waveplates)

(5) Moulds (High strength Al, copper alloy, steel),

- Mould for optics lenses and fiber optic element

- Mould for reflective foils

Fig. 17 shows some of the miniature and micro components listed above.

\subsection{Tooling}

Diamond cutting tool is popularly used in ultraprecision machining for its high thermal conductivity, high hardness and wear resistance and high elastic and shear moduli, which reduce tool deformation during machining. Cutting edge sharpness is crucial to the machined surface quality. The crystalline structure of the diamond enables very sharp cutting edge to be produced. Now a cutting edge in tens of nanometers can be achieved. In addition, special tool for turning may be needed for some complex surfaces. One 
example is the half radius diamond cutting tool for machining large steps diffractive mirrors.

Diamond micro-milling can be used to machining microstructures. In Fraunhofer IPT diamond endmill with a diameter of $300 \mu \mathrm{m}$ has been used for the manufacturing of micro-grooves. An adjustable diamond ball-end mill is used for the fabrication of sculptured surface geometries with optical surface qualities [3].

If an optical surface quality is not required, other types of tools can be used. As shown in Fig. 18 the micro milling tools are made from tungsten carbide with $\phi 0.2 \mathrm{~mm}$ to $\phi 1.5 \mathrm{~mm}$ in diameter. Much work has also been carried out in developing CVD coatings for better wear resistance and improved thermal properties, etc [24].

Nanogrinding using metal bond or resin bond diamond wheels or CBN wheels has been extensively applied for fabrication of glass or ceramic optics. The theoretical and experimental studies on nanometric diamond grinding of glasses show that the average grain size of the wheel is the most significant factor affecting the machined surface roughness. If the wheel with average grain size less than $10 \mu \mathrm{m}$ is used, the grinding of optical glasses in ductile mode can be obtained and the crack will be removed in the well controlled process [25]. Recently some work has been undertaken using the CVD coating for single or multi-layer, micro abrasive tools. Fig. 19 shows a very small abrasive pencil manufactured by coating cemented carbide shanks with a CVD layer [26]. The main advantages of these micro abrasive tools are flexible shape and the small diamond grain 
size of approximately 2 to $12 \mu \mathrm{m}$ [3]. Hence the ductile grinding mode could be achieved. Using these tools different hard and brittle materials such as silicon, aluminium oxide, ceramics and glasses have been successfully ground with high surface quality achieved [3].

In micro machining the minimum feature size is limited by the tool size. With such a mall tool the mechanical stability of the micro tool itself will be crucial for maintaining the product accuracy. Therefore, the tendency in the study of micro tooling seems to be:

- Fabrication methods for minimizing micro tooling

- Optimization of the geometric and coating properties of micro tooling in order to improve tool life and the process accuracy

- Tool holding and balancing as well as micro-tool setting device.

- Micro tooling characterization (machinability in particular)

- Tool condition monitoring during the process

\subsection{Workpiece materials}

Workpiece material properties will play an important role in micro machining. The tendency in the study of workpiece materials will be:

- Size effects and microstructure effects in the micro machining process

- Machinability of a variety of engineering materials and new composite materials, such as glasses, ceramics, metals, plastics, polymers and carbon fiber composites

- Work holding, i.e. stiff clamping within minimum distortion of the workpiece and the difficulty in handling of miniature and micro sized components [8] 


\subsection{Machining processes}

Micro machining is influenced by mechanical, thermal, and chemical loading in the machining contact zone. It is needed to develop a more complete understanding of those loadings on the machining process and the quality of the surfaces generated. In addition, the micro machining process has to become economically reasonable and mass manufacture approach has to be investigated.

The tendency in the study of the machining process will be, but not limited to:

- Multiscale modelling approach (finite element analysis combined with molecular dynamic simulation) for a better understanding of the process and surface generation [27][29]

- Optimizing the machining process and its variables

- Controlling the machining process in respect of the producibility, productivity and predictability.

\section{Concluding remarks}

The markets for miniature and microproducts, especially for those with microstructures and free-form surfaces, hold a high potential of growth. Traditional mechanical ultraprecision machining can be utilized to fabricate miniature and micro components and products with complex shapes in a more controllable way. The indispensable advantage of ultraprecision machining is its applicability to manufacture 3D complex components/devices including micro moulds, dies and embossing tooling for mass 
production of optical and mechanical components. It also provides a cost-effective solution for low volume production or prototyping of MEMS. Machining accuracy depends on machine tool accuracy, tooling, workpiece material and operational factors. The performance of ultraprecision machine tools depends on the accuracy of key elements, including work spindles and motion axes. Bench type ultraprecision machines will be one of the future development tendencies since they may enable ultraprecision machining of miniature and micro products economically and thus the technology affordable for wider audience of manufacturing SMEs. Efforts will also need to be made on the methods for micro tooling fabrication, handling of micro tools and components, tools and components holding and fixturing, and tool condition monitoring during the process. Studies on machinability of a variety of engineering materials and multiscale modelling approach are also needed in order to gain better understanding of the mico machining process.

\section{Acknowledgements}

The authors would like to thank the partners within the EU $6^{\text {th }}$ Framework IP MASMICRO consortium/project (Contract No: NMP2-CT-2004-500095-2) and particularly the partners in its RTD 5 sub-group for the stimulating discussions and meetings, which are very helpful in forming this paper. 


\section{References:}

[1] P. A. McKeown, From micro-to nano-machining-towards the nanometre era, Sensor Review, 16(2) (1996) 4-10.

[2] B. Wybranski, Micro production technologies, mstNews (2) (2004) 43-45.

[3] M. Weck, Ultraprecision machining of microcomponents, Machine Tools (2000) 113-122.

[4] A. H. Slocum, Precision Machine Design. Englewood Cliffs: Prentice-Hall (1992).

[5] P. Schellekens and N. Rosielle, Design for precision: current status and trends, Annals of the CIRP, 47(2) (1998) 557-584.

[6] D. J. Stephenson, D. Veselovac D, S. Manley and J Corbett, Ultra-precision grinding of hard steels. Precision Engineering 2001; 15: 336-345.

[7] H. Shinno, H. Hashizume, Y. Ito and C. Sato, Structural configuration and performances of machining environment-controlled ultraprcision diamond turning machine 'capsule', Annals of the CIRP, 41(1) (1992) 425-428.

[8] N. Ikawa, R. R. Donaldson, R. Kormanduri, W. KÖnig, T. H. Aachen, P. A. Mckeown, T. Moriwaki, and I. F. Stowers, Ultraprecision metal cutting - the past, the present and the future, Annals of the CIRP, 40(2) (1991) 587-594.

[9] P. Stanev, F. Wardle and J. Corbett, Grooved hybrid air bearings, http://www.loadpoint.co.uk/site2/grooved.pdf (accessed on 8th December 2003).

[10] B. Leifheim, Precision and ultraprecision machine tools. Euspen online lecture. http://www.euspen.org/training/lectures/course2free2view/03PrecisionUltraTool/de molecture.asp (accessed on 8th December 2003). 
[11] M. Weck, S. Fischer and M. Vos, Fabrication of microcomponents using ultraprecision machine tools, Nanotechnology, 8 (1997) 145-148.

[12] H. Nakazawa, Principles of Precision Engineering. New York: Oxford University Press, (1994).

[13] B. Cassin, Recent C \& B axis development from Moore Nanotechnology Systems, LLC, http://www.nanotechsys.com/images/PDFs/RecentC\&BAxisDevelopments.PDF (accessed on 30 March 2005)

[14] Nanotech 350 UPL brochure, Moore Nanotechnology systems Ltd. http://www.nanotechsys.com (accessed on 15 March 2005).

[15] Nanotech 500 FG brochure, Moore Nanotechnology systems Ltd. http://www.nanotechsys.com (accessed March 2005).

[16] PicoAce brochure, Loadpoint Ltd., http://www.loadpoint.co.uk/picoace/picoace.htm (accessed on 5th January 2004).

[17] 5-axis machining center micromaster ${ }^{\circledR}$ MM, Kugler Company Brochure, www.kugler-precision.com (accessed on December 2003).

[18] Robonano $\alpha$-0iA brochure, Fanuc Ltd., http://www.fanuc.jo/en/product/robonano (accessed on 12th December 2003).

[19] O. Rübenach, Micro technology - applications and trends. Euspen online training lecture.http://www.euspen.org/training/lectures/course2free2view/02MicroTechAp ps/demolecture.asp (accessed on 18th December 2003).

[20] A. EI-Fatatry and A. Correial, Nanotechnology in Microsystems: potential influence for transmission systems and related applications. mstNews (3) (2003) 25. 
[21] H. Huang, W. K. Chen, L. Yin, Z. Xiong, U. C. Liu and P. L. Peo, Micro/meso ultraprecision grinding of fibre optic connectors, Precision Engineering, 28(1) (2004) 95-105.

[22] KERN Micro- und Feinwerktechnik GmbH \& Co. KG, http://www.kernmicrotechnic.com (accessed on $23^{\text {rd }}$ March 2005).

[23] T. Dow, E. Miller and K. Garrard, Tool force and deflection compensation for small milling tools, Precision Engineering 28(1) (2004) 31-45.

[24] J. Webster and M. Tricard, Innovations in abrasive products for precision grinding, Annals of the CIRP, 53(2) (2004) 597-642.

[25] M. Chen, D. Li D, S. Dong and F. Zhang, Factors influencing the surface quality during ultra-precision grinding of brittle materials in ductile mode, Key Engineering Materials (257-258) (2003) 201-206.

[26] J. Gabler, H-W. Hoffmeister, B. Menze and L. Schafer, Micro-abrasive pencils with CVD diamond coating, Diamond Relat. Mat, 13(3-7) (2003) 707-710.

[27] X. Liu, R. E. Devor and S. G. Kapoor, The mechanics of machining at the microscale: assessment of the current start of the science, Transactions of the ASME: Journal of Manufacturing Science and Engineering, 126 (2004) 666-678.

[28] http://www.rockwellautomation.com/anorad/products/linearmotors/, accessed on $9^{\text {th }}$ May 2005.

[29] X. Luo, K. Cheng and R. Holt, An investigation on the mechanics of nanometric cutting and the development of its test-bed, International Journal of Production Research, 41(7) (2003) 1149-1165.

[30] www.masmicro.net, accessed on $9^{\text {th }}$ May 2005. 


\section{List of the captions of the figures}

Fig. 1 Schematic figure of an ultraprecision milling machine.

Fig. 2 Hybrid air bearing milling spindle for UPM 3.

Fig. 3 Construction of device for measuring displacement of sliding surface of LODTM.

Fig.4 Design procedures.

Fig. 5 Nanotech 350 UPL.

Fig. 6 Nanotech 500FG.

Fig. 7 PicoAce grinding machine

Fig. 8 MICROMASTER MM 5-axis milling machine.

Fig. 9 Robonano $\alpha-0 i \mathrm{~A}$ and its motion axes layout

Fig. 10 Application market of microproducts.

Fig. 11 Application market of microproducts by disciplines.

Fig. 12 Silicon wafer structuring

Fig. 13 Ground spherical end faces of fibre optic connector.

Fig. 14 Fast Tool turning: multifaceted integrator mirror for laser beam shaping.

Fig. 15 Injection mould for watchmaking.

Fig. 16 Design layout of a bench type micro-milling machine

Fig. 17 Some miniature and micro components

Fig. 18 Micro milling tools.

Fig. 19 CVD coated abrasive pencil. 


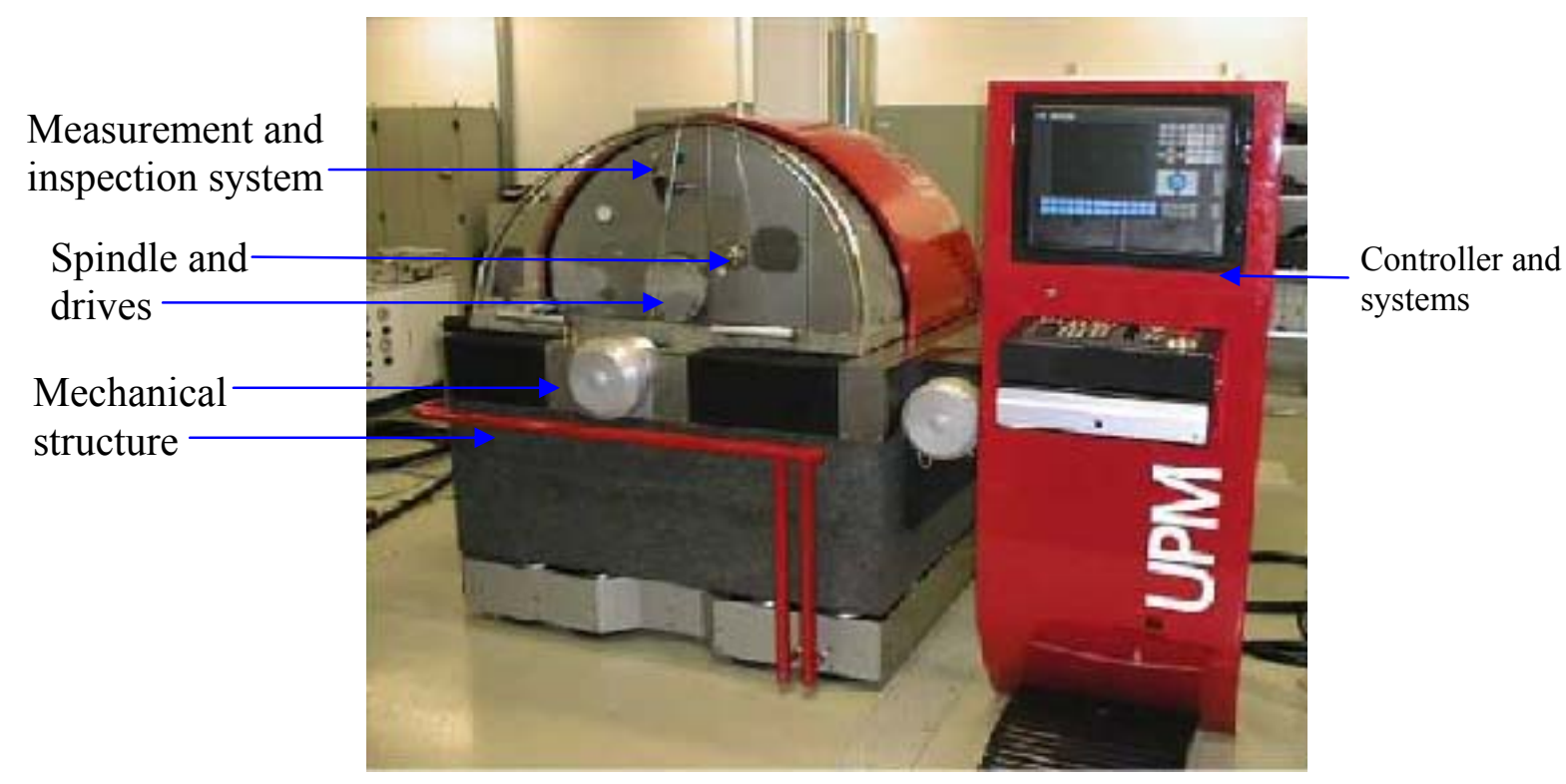

Fig.1 Schematic figure of an ultraprecision milling machine [3].
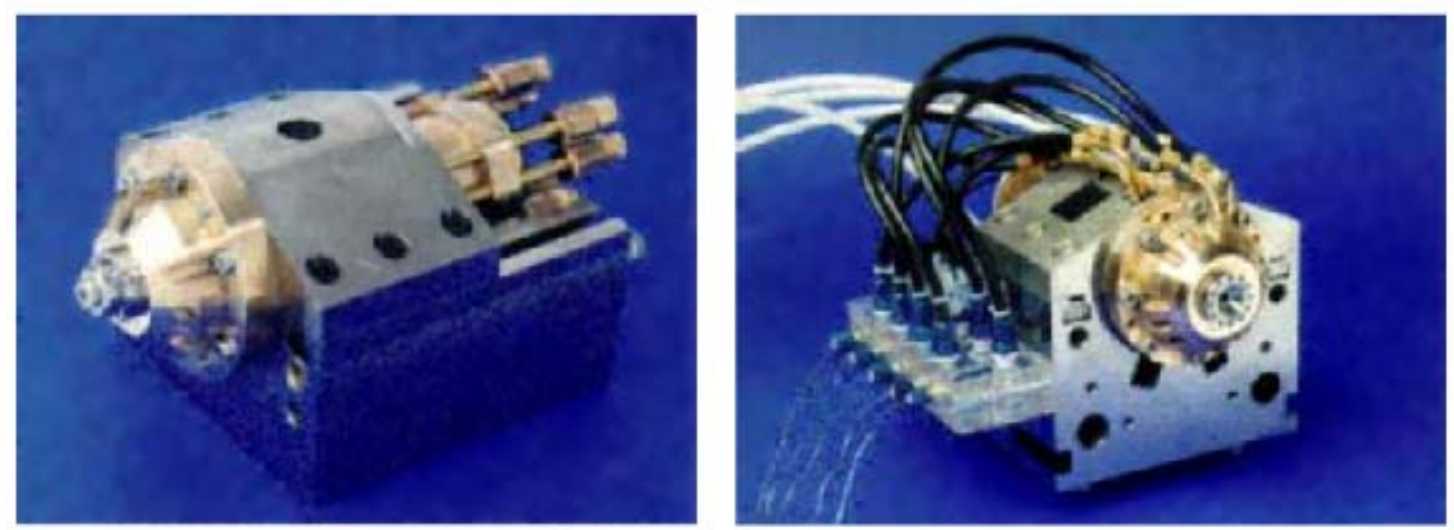

Fig. 2 Hybrid air bearing milling spindle for UPM 3 [10]. 


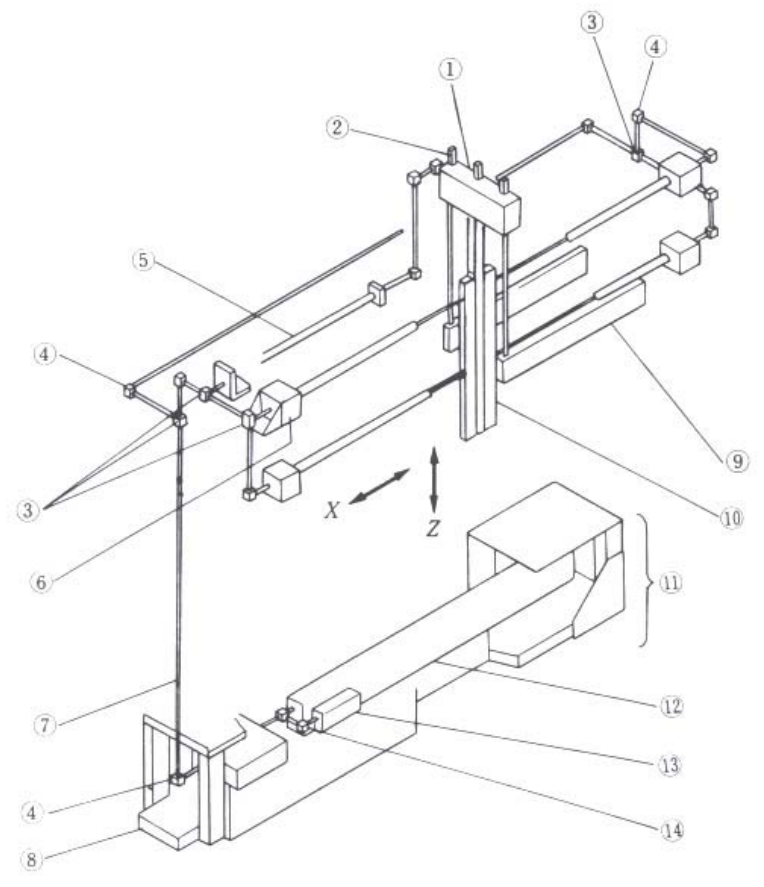

Fig. 3 Construction of device for measuring displacement of sliding surface of LODTM [12].

1 Upper optics box three interferometer in vacuum system 2 Detector (three)

3 Beam splitter $\quad 4$ Swing mirror 5 Bellows, at six locations within the vacuum system

6 Interferometer cover (4) and detector (4) within 7 Beam cover 8 Optics bench

$9 \mathrm{Z}$ axis straightedge $10 \mathrm{X}$ axis straightedge 11 Supper for laser optics unit

12 SP 125 helium/neon laser 13 Helium/neon laser with stabilized iodine

14 Feedback detector 


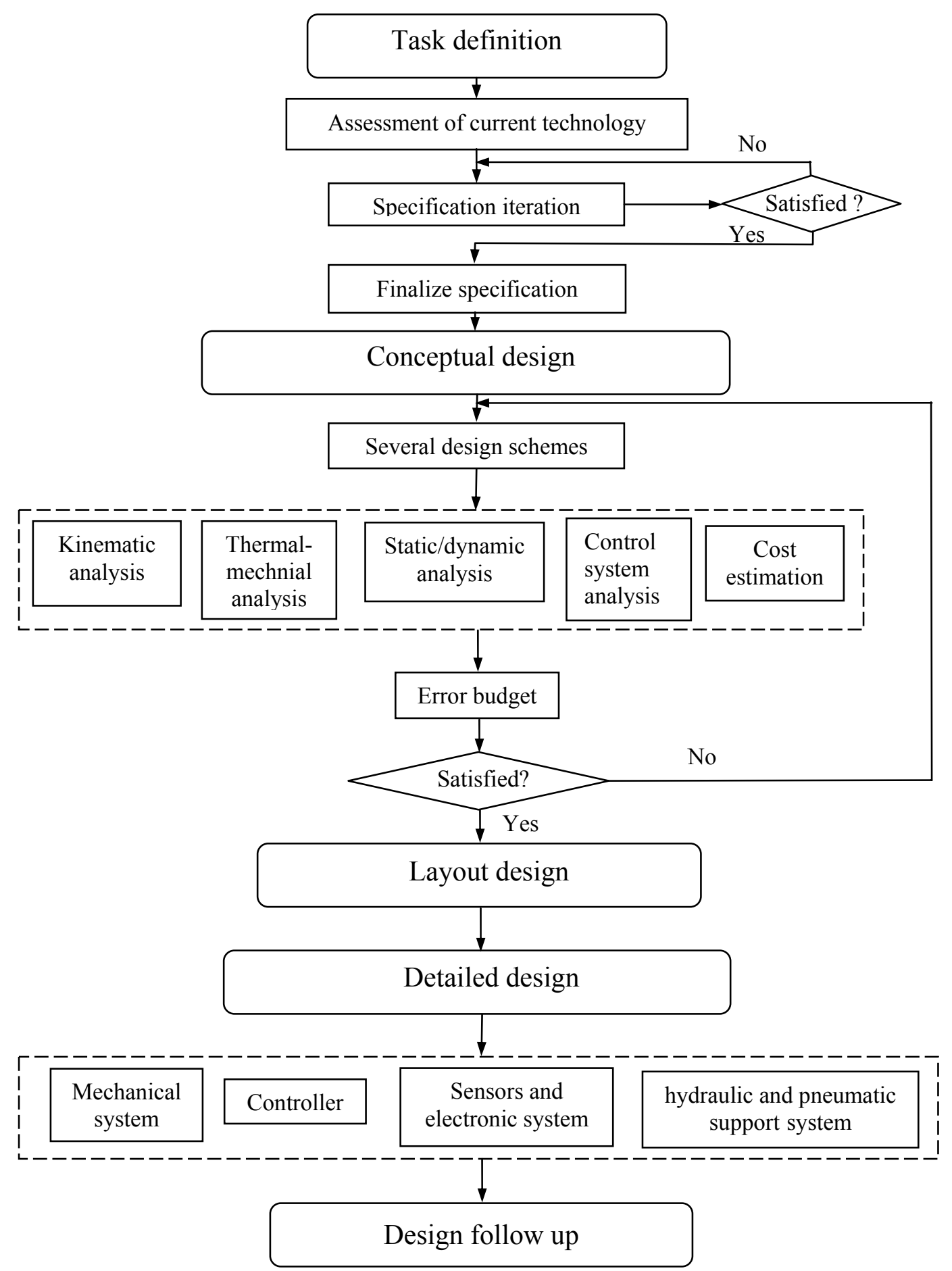

Fig.4 Design procedures. 


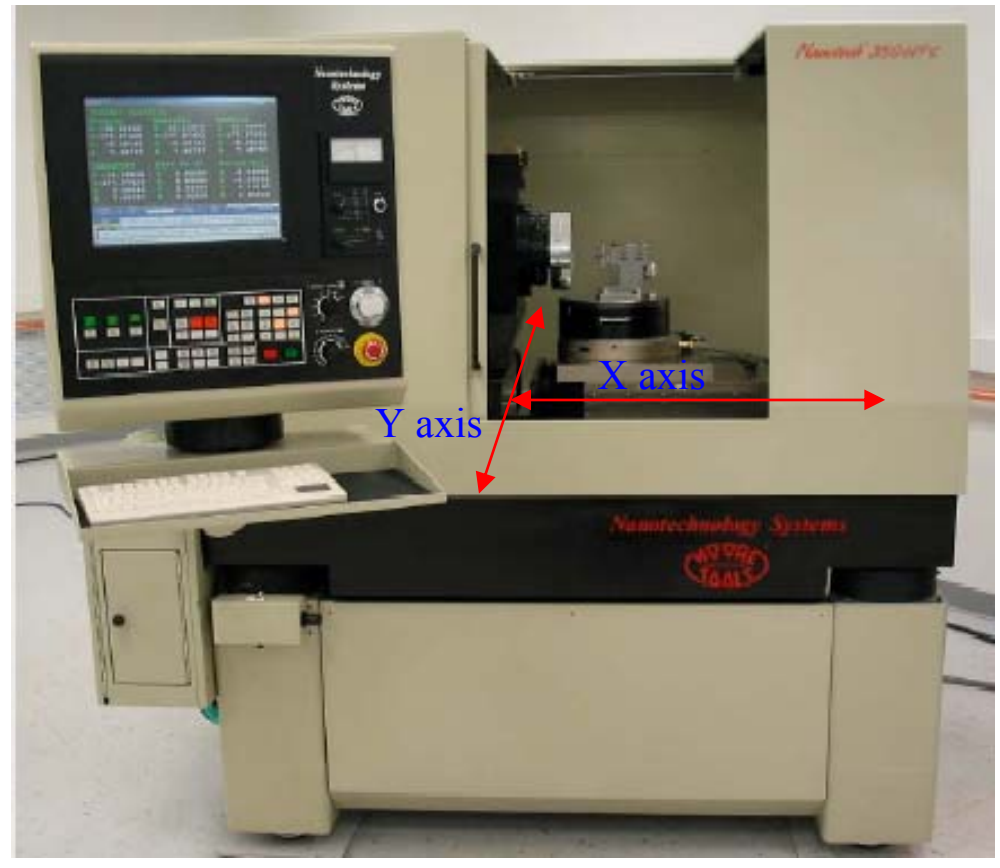

Fig. 5 Nanotech 350 UPL [13].

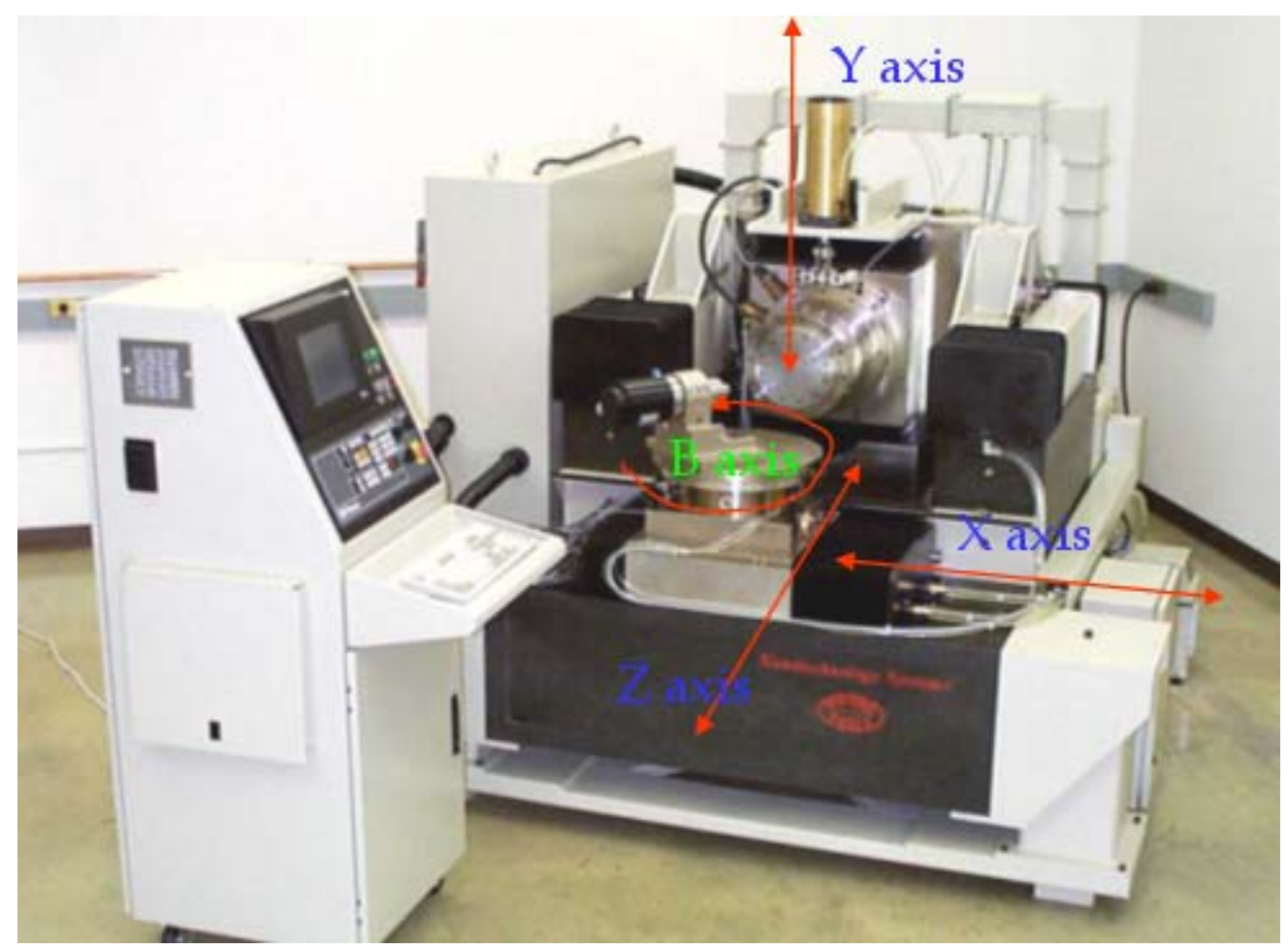

Fig. 6 Nanotech 500FG [15]. 


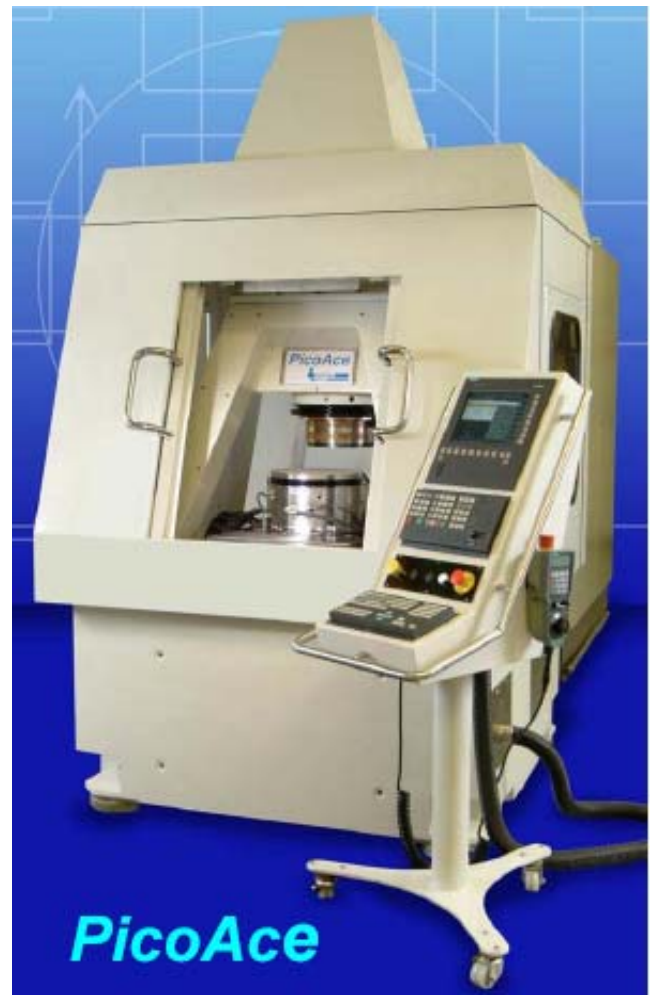

Fig. 7 PicoAce grinding machine [16].

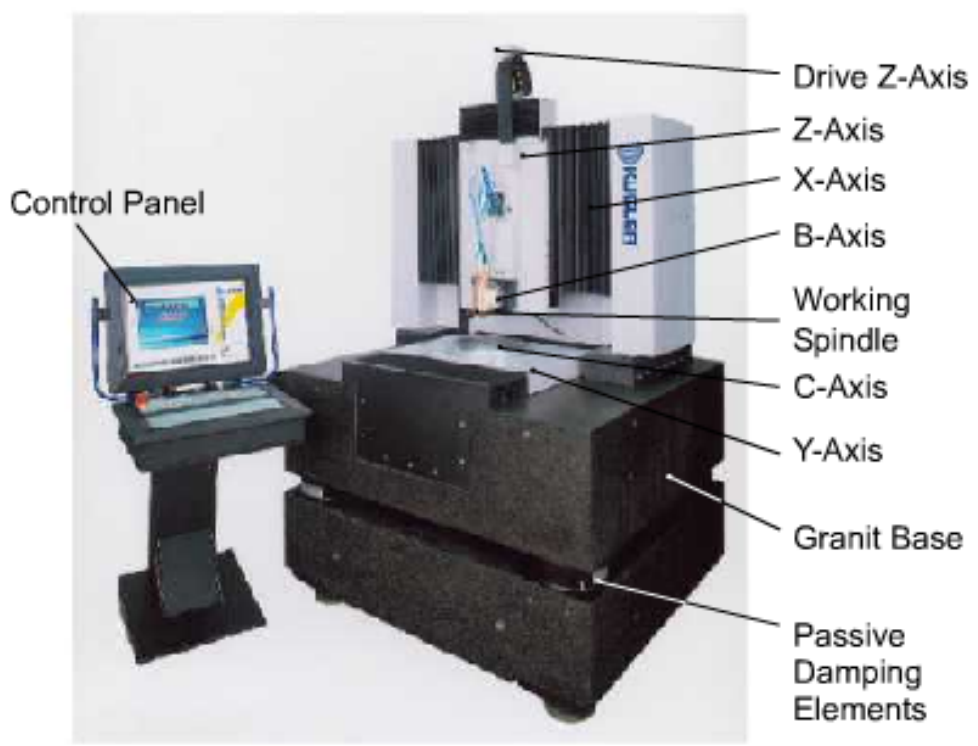

Fig. 8 MICROMASTER MM 5-axis milling machine [17]. 

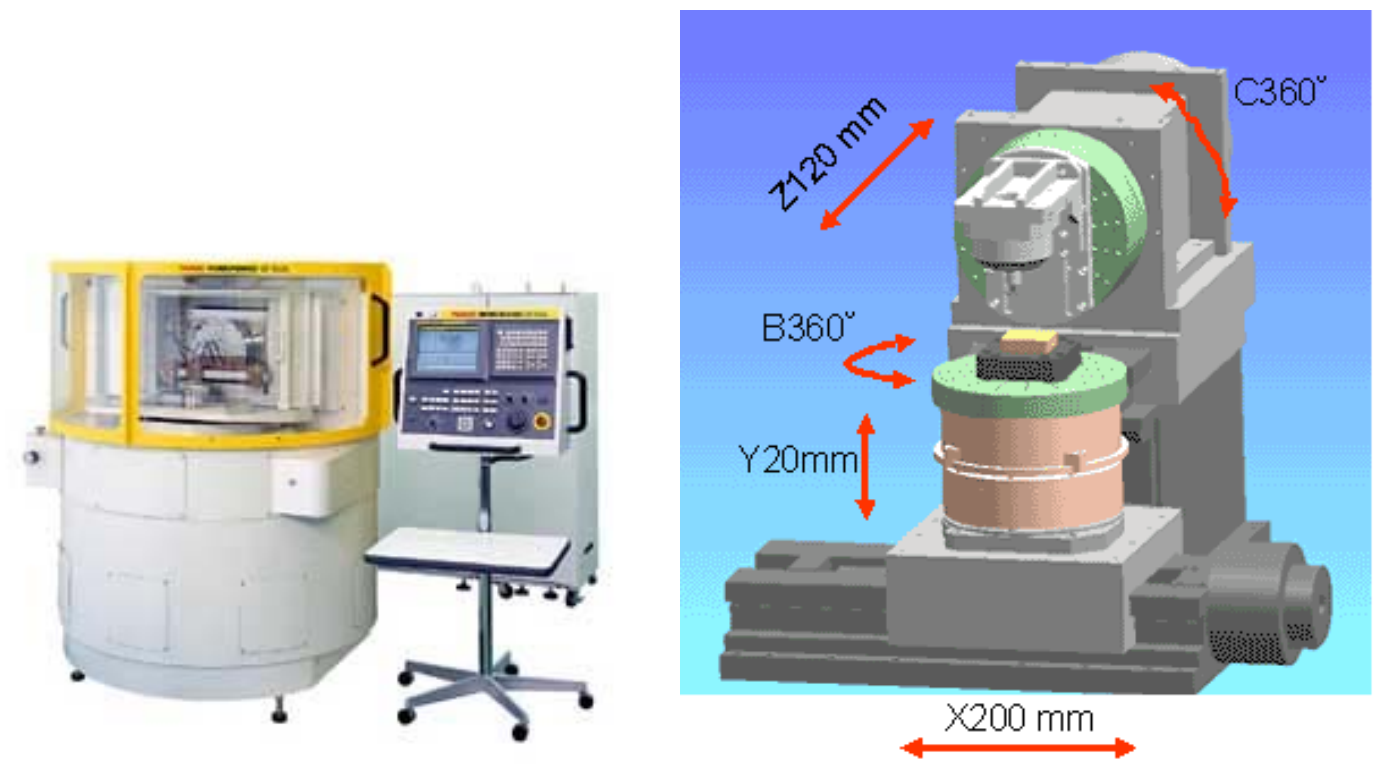

Fig. 9 Robonano $\alpha-0 i \mathrm{~A}$ and its motion axes layout [18].

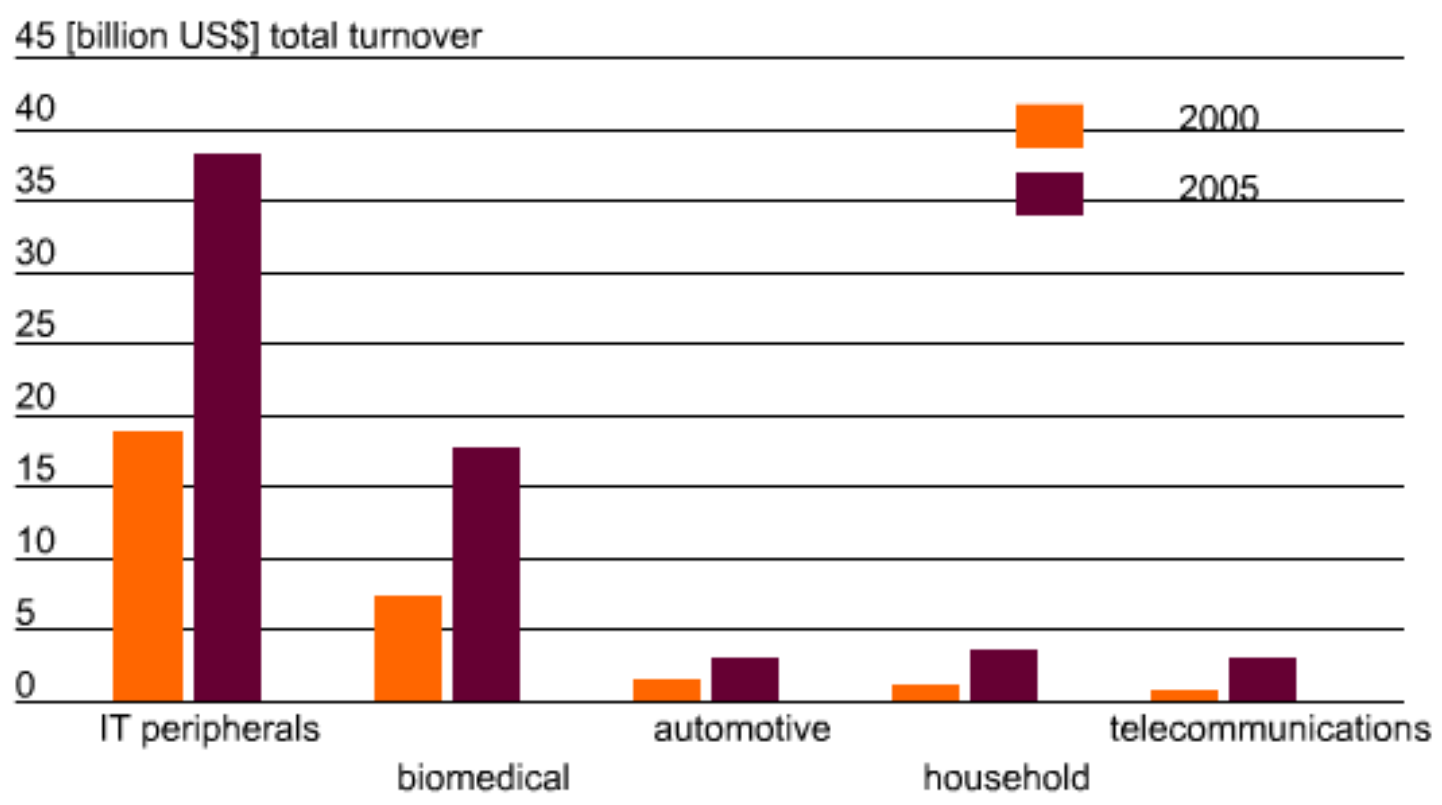

Fig. 10 Application market of microproducts [19]. 
Small number of MST products relies only on electronics.

On the other hand electronics is integral part of almost all MST products.

Mechanics is today of bigger importance for MST products.

The importance of optics will even those of mechanics in the future.
70 [billions US\$] total turnover

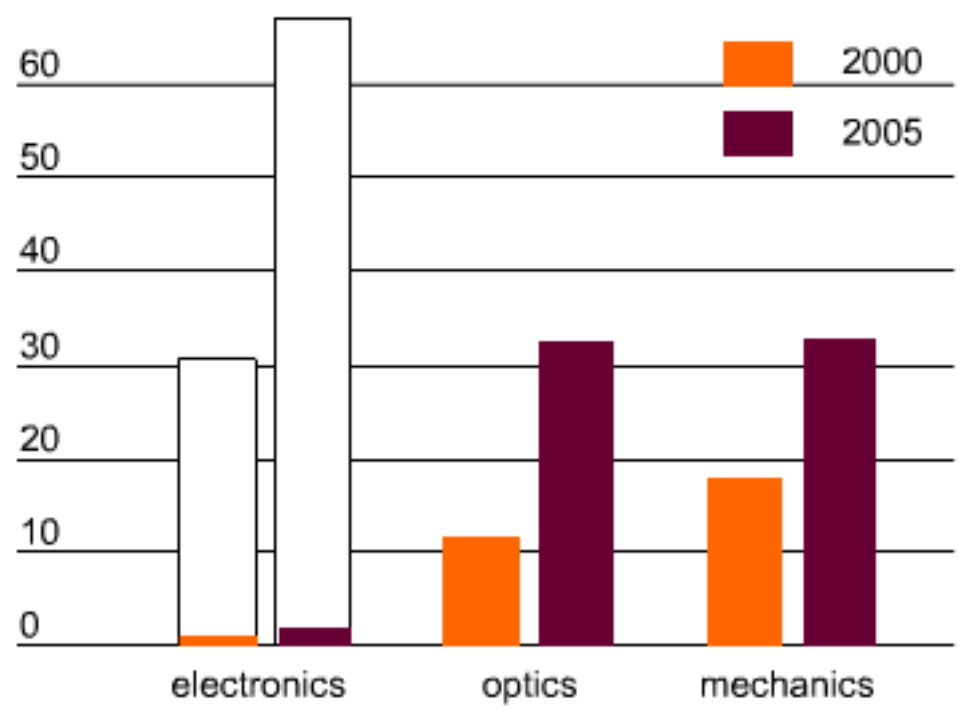

Fig. 11 Application market of microproducts by disciplines [19].

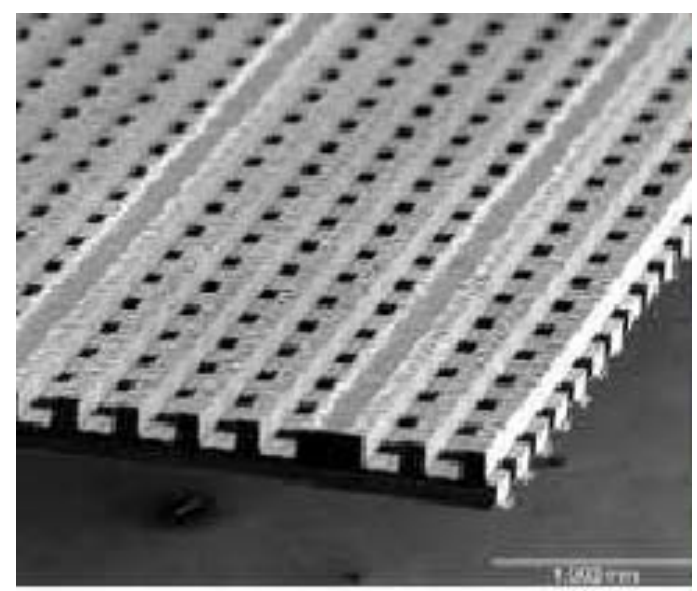

Fig. 12 Silicon wafer structuring [20]. 


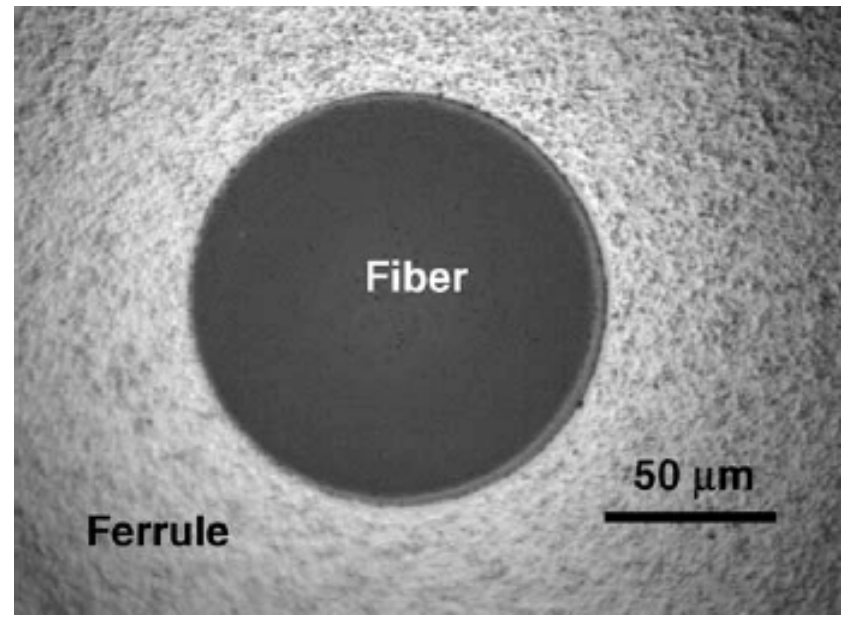

Fig. 13 Ground spherical end faces of fiber optic connector [21].

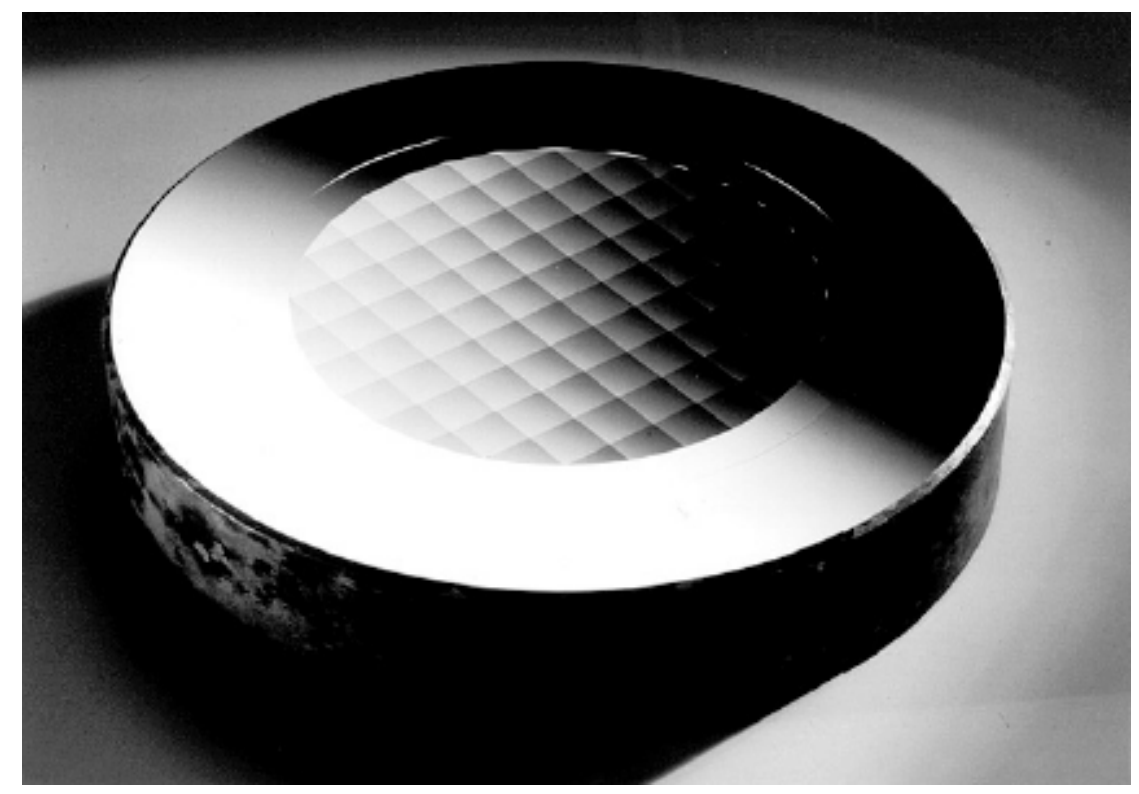

Fig. 14 Fast Tool turning: multifaceted integrator mirror for laser beam shaping [11]. 


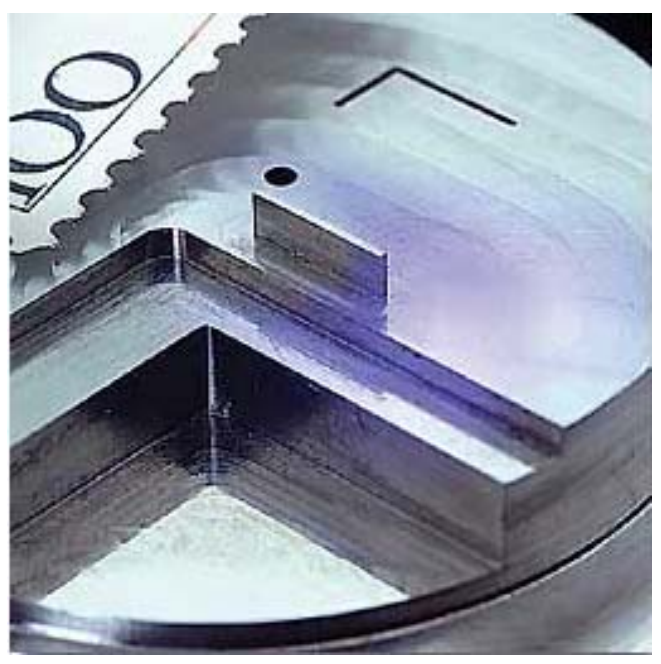

Fig. 15 Injection mould for watchmaking [22].

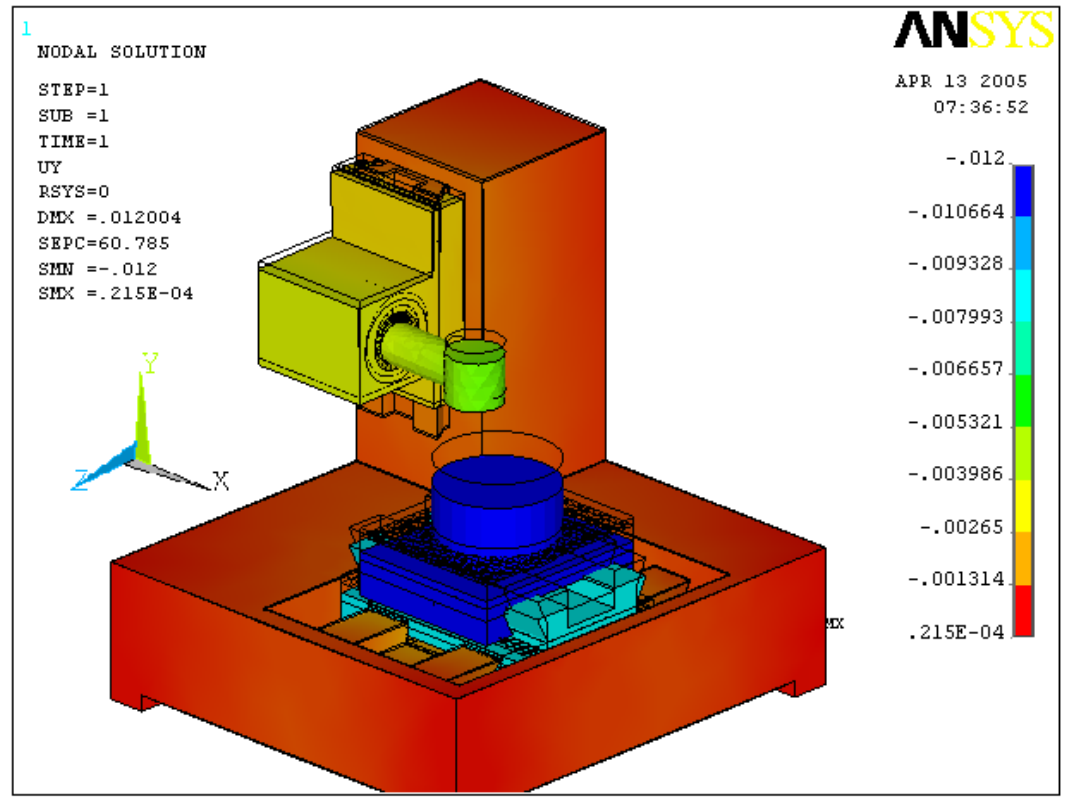

Fig. 16 Design layout of a bench type micro-milling machine 


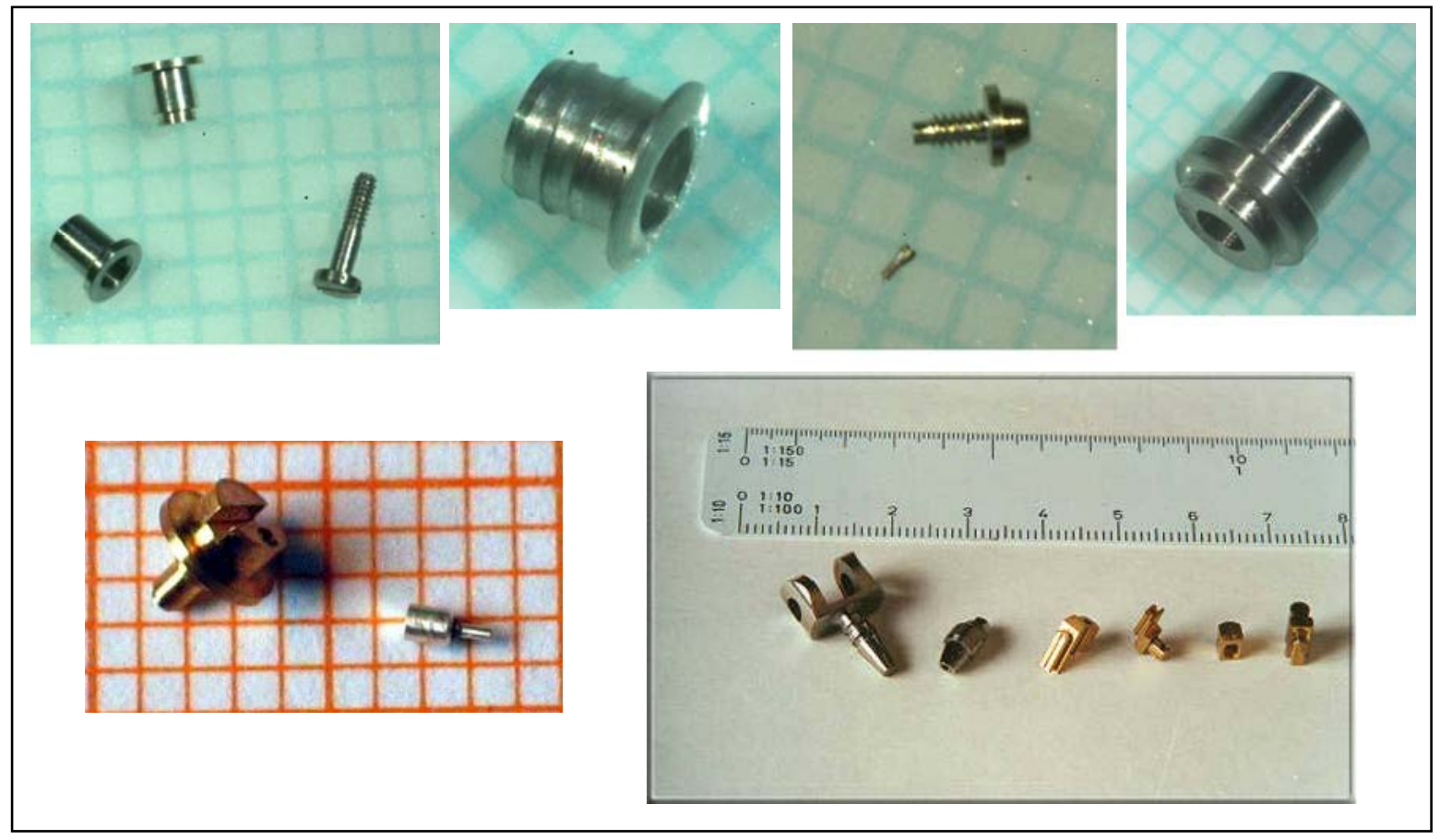

Fig. 17 Some typical miniature and micro components (Courtesy to KERN Micro-und Feinwerktechnik and Pinol A/S)

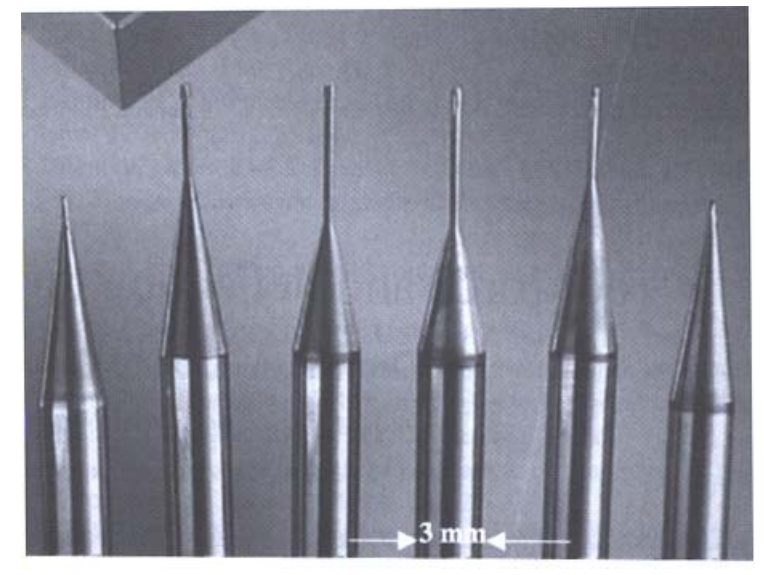

Fig. 18 Micro milling tools [23]. 


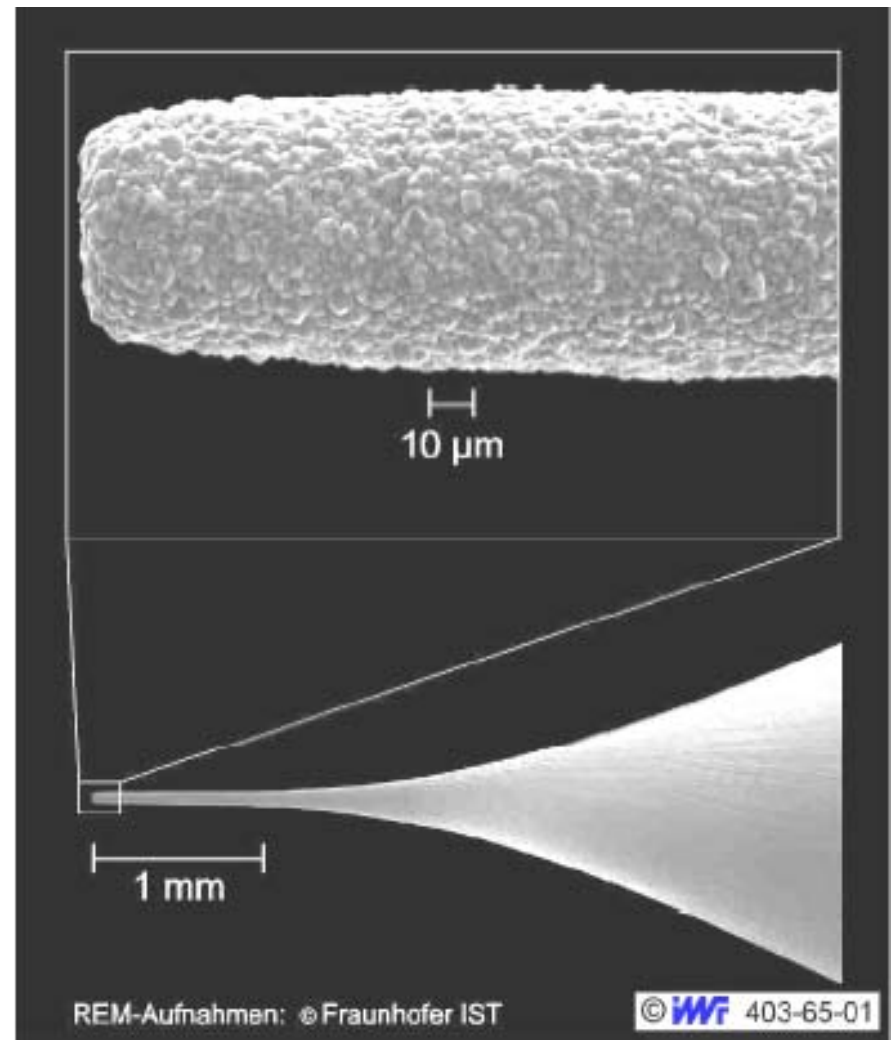

Fig. 19 A CVD coated abrasive pencil [25]. 